\title{
Study on Influence on National Identity Sense of Preschool Children by Traditional National Sports
}

\author{
$\mathrm{Li} \mathrm{Li}$ \\ Shaanxi Xueqian Normal University \\ Xi'an, China
}

\begin{abstract}
Traditional National S ports is formed in the long process of development of Chinese nation within the scope of national traditional culture. Offering more traditional sports to preschool children can make them contact and learn about their own national culture, customs and habits more comprehensively, playing an important role in cultivation and strengthening of national cultural characteristics. And the influence on sense of national identity of preschool children by Traditional National $S$ ports is discussed in this paper.
\end{abstract}

Keywords-Traditional National Sports; preschool children; sense of national identity; influence

\section{MEANING OF TRADITIONAL NAT IONAL SPORT S AND SENSE OF NATIONAL IDENTITY}

\section{A. Traditional National Sports}

The concept of "Traditional National Sports" was proposed for the first time in the late 1970s in China, and relevant book where this concept first appeared is "Abridged Edition of China's Modern Sports" of Year 1979 compiled by Chengdu Sport University. The relatively complete definition of Traditional National Sports in this period is: "Activities of Traditional National Sports can be divided into five categories differing in content, namely physical activity with some military significance, activity relevant to race multiplication, activity relating to national origin, and activity having a certain relationship with labor and production, and the activities playing a reflection role in national regeneration or renaissance." The improvement of this definition is that it has stressed "tradition" in culture, and has taken into consideration of the particular characteristics of various ethnic groups owned by Chinese nation, stressing on social attributes and natural attributes of Traditional National Sports.

\section{B. Sense of National Identity}

Sense of national identity is also called identification nature. Specifically, people who belong to a same nation will believe that they are a community with people of their own, which is a psychological feeling. It was also said that national identity is a structure, and the sense of belongings generated by individual toward groups, individual participation in group activities and positive thoughts of individual toward their group are all included in this complex structure. In my opinion, this definition of sense of national identity is only a concept in narrow sense.

The concept of national identity in broad sense shall include not only their feelings, attitudes and behavior intervention about the nation they belong to, but also the feelings, attitudes, and behavior intervention of individuals toward other nations. If one country has only one nation, then national identity will be often counted as state identity. But if the country has a lot of nations, then the level of state identity is higher than that of national identity, for instance, sense of national belonging, national society participation, practice of national culture and sense of national self-identity are all included in it. So, as for Chinese preschool children, national identity is constituted by the following three aspects: First is to have a common ethnic origin, no matter the Han nationality or other minorities; second is to have a common national culture; and finally we all belong to the same country, namely China. The sense of national identity of the entire Chinese nation is constituted jointly by the three aspects.

\section{SIGNIFICANCE OF TRADITIONAL NAT IONAL SPORT S EDUCATION FOR PRESCHOOL CHILDREN AND SCHOOL}

\section{A. Significance for Students}

1) Beneficial to Physical and Mental Health of Children.Western sports culture contains certain concept of survival of the fittest, which advocates people to compete freely. Under such concept, the body and physical ability of children will get a relatively large improvement, but it has ignored the unique features of Traditional National Sports, such as self-cultivation, mental conditioning and the like. Traditional National Sports contains unique oriental philosophical viewpoint, stressing from being to nonbeing and from the inside out, focusing on the meaning of life and self-worth. As a result, we can cultivate personality of preschool children better through traditional national sports to shape and educate from aspect of spirit. Meanwhile, Traditional National Sports owns excellent fitness and entertainment features, and children will enjoy the pleasant of sports in this process with healthy physical and mental development and better comprehensive quality.

2) Conducive to Help Children form Team Spirit from an Early Age with Better Cohesion. As for the Chinese nation, Traditional National Sports is a flower bloom in it absorbing 
nutrients from the vast land of China, and the excellent Chinese national spirit, national culture, national moral emotion and national life concept etc. are all included in it with strong and abundant cultural heritage and ethnic nature. When conducting Traditional National Sports, children will contact more national culture and produce a more intuitive idea. Such improvement of identity sense will help to develop children's sense of national pride and strengthen cohesion.

\section{B. Significance for School}

1)Enrich Teaching Resources of School. If the process of globalization and modernization have accelerated a lot, and traditional western concept has infiltrated every aspect of our national life, the physical education from kindergarten to university are influenced by western sports, and all sports subjects take sports competition as main subjects in favor of western styles such as soccer, basketball, etc., which has become a default sport project of Chinese people, the curriculum setting will become very simple, which is unfavorable for the development of children and not in line with social requirements. Traditional National Sports is a branch of physical education with the characteristics of games, practice and skills. Schools and teachers shall develop potential resources from traditional national sports, and then form a physical education course for children through integration and improvement. Thus school education is supplemented with further development and deepening, enriching resources of physical education, and the diverse curriculum structure which has been optimized will become more diversified with ultimate entire physical education reform being realized. Moreover, different regions have their own cultural characteristics and become more colorful after these characteristics have integrated in sport projects, being able to better inherit local folk culture.

2)Beneficial to Better Construction of Campus Culture. Campus culture is included in social culture, representing the unique campus spirit and cultural atmosphere, with components of both material culture and spiritual culture. Although nowadays the society and schools are paying more attention to the construction of campus culture with various activities, but there is not their own characteristics and the heritage of national spirit. The introduction of Traditional National Sports into schools will also bring in rich folk traditional culture, allowing more colorful cultural activities on campus, so the campus culture will become stronger, and each school will have its own cultural characteristics. Although this spiritual culture is invisible, but the impetus it has brought about is enormous.

\section{Impact of Traditional National Sports on Preschoolers' Sense of National Identity}

1) Starting from Native Culture to Cultivate Children's National Characteristics. The cultural traditions of a country shall not be abandoned at any time, which is the essence of a nation's spirit. Chinese nation has a history of thousands of years, which can be described as long standing, including a large number of ethnic minorities which also have a long history. Traditional National Sports is a very effective way for the national cultural heritage. And we shall pay attention to take current and future specific needs as a starting point in combination with preschool children's own characteristics. The content selected shall meet the age characteristics of children, and pay attention to funny expressive forms so that the children love to see and hear. Thus preschool children can tell a better understanding and recognition of national traditional culture. China has been always attaching great importance to early childhood education, and there are a lot of contents suitable for preschool education in traditional culture, such as respecting the old and cherishing the young, tolerance, benevolence and filial piety, humility and respect as well as helping each other. These ethical ideas are very excellent and worthy of being carried forward; and from the perspective of form, there are national dances with various national characteristics as well as national sports activities such as kite flying, ju mping rope, hide and seek and rolling hoop filling with fun accompanied by great arbitrariness and selectivity, which can be said the very good material, influencing the young children with traditional culture in a subtle way.

China is a country with many ethnic groups, and each nation has its own sparkling culture, which can enrich resources for education. Such music and folk crafts with ethnic characteristics etc. can be brought in physical education for children. For example, the unique children's songs and children's folk rhy mes etc. have not only showed a nation's self-esteem and pride, but also allowed children to see the local customs, geographical features and so on. Teachers can apply these children's rhymes and songs to sports activities, making children aware of the existence of mu lticulturalism while play ing and keeping fit, thus they will gradually understand and respect these various cultures, to reach the final result of cultivating the sense of national identity.

2) Make Children Maintain better National Cultural Traditions to Enhance Their Sense of National Identity. Currently, the development trend all over the world is globalization and modernization with faster speed and wider coverage. The main body of national culture is the native culture, and this trend is unavoidable in any situation which will affect the changes and development of all nation culture. As a result, how to maintain the diversity of national culture in this era of globalization, and strive to achieve "harmony in diversity" become particularly important, especially for the Traditional National Sports.

3) Enhance National Cohesion, Cultivate Patriotic Spirit from Childhood. Traditional Chinese National Sports has a long history with profound and rich cultural connotations, and have their own form of expression. It is not only a simple sport, but also an emotional connection, playing a role of maintenance for the great rejuvenation of Chinese nation. It can also be taken as a carrier to spread our traditional culture. For example, the dragon and lion dance is a sport common in Chinese people to express joy and blessings, as the dragon symbolizes the Chinese nation and we often refer to ourselves as "descendents of the dragon". The dragon culture is of far-reaching influence and significance for the cultural development of Chinese nation. 
Teachers can bring children to visit the lion and dragon dances, and conduct practice themselves, thus the children will feel strong national characteristics in the fields of clothing, music, props and so on.

Patriotism is a very important national spirit, and for thousands of years, the majority of Chinese people have cultivated their moral sentiments under the influence of national spirit of patriotis $\mathrm{m}$. A nu mber of martial arts masters have emerged under such background as well, defending the national interests with their superb martial arts. Many people who practice martial arts disregard their personal life and death, to come forward to ease the critical situation of country and nation, making contribution to defend integrity of the country and independence of the nation. As for preschool children, learning some martial arts matched with their age appropriately will not only be beneficial for their physical health, but also can better shape their spirit of patriotism, and experience the "self-reliance" and "virtuous" in national spirit through learning and appreciation of the martial arts morality. But presently, many shortcomings exist in the development of martial arts in school, therefore, it is necessary to carry out effective reform, work out a martial art system which is simple with high feasibility and suitable for children with emphasis on education of martial arts morality.

4) Develop Good Team Spirit, Carry Forward Traditional Chinese Virtues. Many traditional national sports have a strong collectivity, requiring members to carry out their own duties with clear division of labor. The members must have a good team spirit to ensure ultimate success. The common traditional sports that need everyone's coordination are tug of war or collective jumping rope, of which the advantages are simple and feasible, and do not need too much space and particular equipment, being able to be carried out easily. Through these projects, the children will not only get exercise, but also learn more about how to communicate with others. Team spirit is formed in this process in a subtle way. At the same time, the excellent contents of our traditional culture, such as fighting spirit for sticking out, team spirit with sincere cooperation, have been reflected in the process of participation in sports and other activities, so preschool children can better understand the traditional virtues of Chinese nation and carry them forward.

\section{Methods and Measures to Carry Out the Traditional National Sports in Kindergarten}

China's Traditional National Sports has a very rich content, including a lot of aspects, such as the aspects of entertainment and gaming, capacity and athletics and so on. From the perspective of today's social requirements and the objectives of national education, there are mainly the following aspects:

First of all, allow preschool children to learn about the spirit of our nation, including the spirit of patriotism, national dignity and self-confidence. For instance, in the Dragon Boat Festival, we can lead the children to watch dragon boat races, and in this process, tell them about $\mathrm{Qu}$ Yuan and his deeds, to foster children's spirit of patriotism, enabling them to have a better understanding of the spirit of "mighty can not be subdued".

Second is a specific behavior of education and lifestyle. Many of folk sports activities have certain constraints on the behavior, for instance, we shall go hiking and fly a kite on Tomb Sweeping Day, conduct dragon-boat racing at Dragon Boat Festival, and make dragon and lion dances in Spring Festival. What need to do is to take better use of these customs with behavior restrict, enabling children to develop a good habit and ideological atmos phere from an early age.

Third is the education about psychological regulation. Traditional National Sports has laid little emphasis on skills, as it mainly pays attention to environmental harmonious and friendly, such as hide and seek, group kite flying, swing etc., enabling children to feel warmth, enjoy the pleas ant of sports; and martial arts, climbing etc. are to train a relatively strong character.

Education about self-care is the last aspect. Five-Animal Exercises and Tai-chi-chuan are containing the knowledge about self-cultivation and health care, rendering children a psychological adjustment during the process of fitness. Given the children are still very young, and teachers shall select the targeted contents about self-care in combination with their physical and mental characteristics.

\section{REFERENCES}

[1] Wang Zhihui. Totem Worship and Religious Belief: Spiritual Strength of Traditional National Sports Cultural Heritage [J]. Sports \& Science, 2012, 33(6): 12-17.

[2] Shao Yuping. Study on College Educational Heritage and Protection of Intangible Cultural Heritage of Traditional National Sports [J]. Journal of Guangxi Normal University (Philosophy and Social Science Edition), 201 1, 47(6):115-118.

[3] Sheng Jie. Study on Value of Opening Up Traditional National Sports Teaching in Five-year Higher Vocational Schools [J]. Fighting · Wushu Science, 2013, (3):94-95.

[4] Ma Yanjun. Role of Traditional National Sports in Cultural Construction [J]. People's Tribune, 2012, (26):200-201.

[5] Zhang Jinfeng. Connotation and Development Path of "Soft Power" in Traditional Sports Culture of Minority in Yunnan [J]. Journal of Yuxi Normal University, 2013, 29(3): 55-57.

[6] Lin Yunfei. Cultivation of Social Regulatory Function and National Spirit in Traditional Sports Culture of Minorities [J]. Science \& 